\title{
USING A PUBLICATION ANALYSIS TO EXPLORE MISSION SUCCESS
}

by Steven A. Ackerman, Jean M. Phillips, Thomas A. Achtor, and Daniel S. Bull

A federally-funded research center assesses its performance by examining and categorizing its publication patterns with quantitative and qualitative metrics.

I ndicators of a successful research center include the number of publications in refereed journals, proposal success rates, the number of graduating graduate students, awards of recognition, international scientist exchange programs, conference presentations, and software distribution. At a research university, the number and quality of publications are credible evidence of the value of a research group. Access to electronic databases permits analysis of an institute's publishing record with special regard to the organization's mission.

AFFILIATIONS: ACKERMAN-Cooperative Institute for Meteorological Satellite Studies, and University of WisconsinMadison, Madison, Wisconsin; PHILLIPS AND BULL-Space Science and Engineering Center, Madison, Wisconsin; ACHTOR-Space Science and Engineering Center, and Cooperative Institute for Meteorological Satellite Studies, Madison, Wisconsin CORRESPONDING AUTHOR: Steven A. Ackerman, Department of Atmospheric and Oceanic Sciences, University of WisconsinMadison, 1225 West Dayton St., Madison WI 53706

E-mail: steve.ackerman@ssec.wisc.edu

The abstract for this article can be found in this issue, following the table of contents.

DOI:10.1175/2009BAMS2810.1

In final form 27 March 2009

(C)2009 American Meteorological Society
Historically, citation analyses for evaluative purposes compare one unit against a control group (e.g., Kostoff 2002). This paper analyzes articles published in refereed journals by the staff at a research institute within the University of Wisconsin-Madison to explore how the institute is addressing its mission goals. The analysis is made with reference to historical trends in the number of publications, publishing history, subject areas, venues, and collaborators. The next section briefly describes the research institute, its three mission statements, and its personnel. The data collection methodology is then described followed by an examination of the results. Finally, the results are summarized, emphasizing areas of success and those in need of attention.

BACKGROUND OF CIMSS. The Cooperative Institute for Meteorological Satellite Studies (CIMSS) was formed through a Memorandum of Understanding between the University of WisconsinMadison (UW-Madison), the National Oceanic and Atmospheric Administration (NOAA), and the National Aeronautics and Space Administration (NASA). The formal relationship of CIMSS with NOAA began in 1980, with NASA joining in 1990. The CIMSS mission includes the following three goals:

- to foster collaborative research among NOAA, NASA, and the university in those aspects of 
atmospheric and Earth system sciences that exploit the use of satellite technology;

- to serve as a center at which scientists and engineers working on problems of mutual interest can focus on satellite-related research in atmospheric and Earth system science; and

- to stimulate the training of scientists and engineers in the disciplines involved in atmospheric and Earth sciences.

To achieve these goals CIMSS conducts a broad array of research and education activities. The primary asset of CIMSS is its research staff. CIMSS has experienced a steady increase in the size and scope of its research programs over its 27-yr history. Figure 1 shows the number of CIMSS associates over the past $15 \mathrm{yr}$. The size of the CIMSS staff has more than doubled during the period from 1995 to 2007. The number of CIMSS principal investigators (PIs) who are submitting proposals and leading research projects totaled 21 in 2008 (Fig. 2). The CIMSS support staff are primarily atmospheric scientists and programmers, but their expertise is wide ranging, providing strong support for a variety of programs. CIMSS conducts its research by building teams to accomplish program goals. The staff can move from one project to another or work on multiple projects to provide expertise and stability to the CIMSS research program. CIMSS annually supports 15-20 graduate students, with CIMSS PIs serving as science advisors to their research projects. CIMSS has a long history of scientist exchange, especially through international collaborations. Extended-term scientist exchange programs exist with agencies in China, Australia, and Europe.

METHODOLOGY. The UW-Madison's Schwerdtfeger Library has collected information on CIMSS publishing practices since the institute

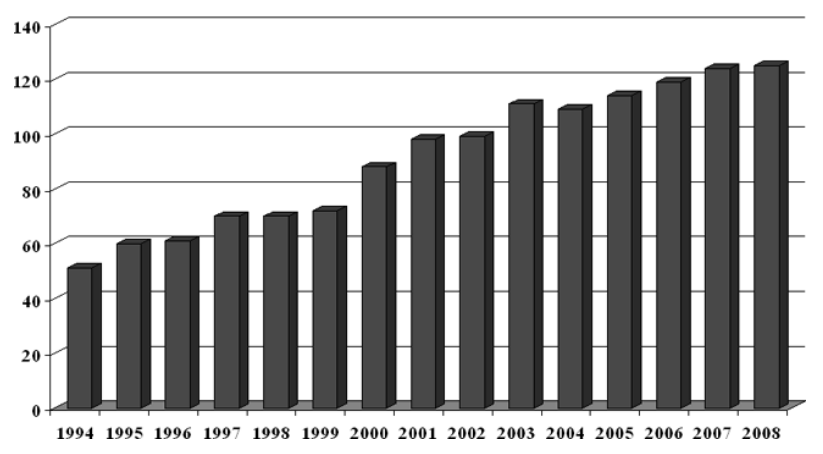

FIG. I. CIMSS staff (including students) from 1994 through 2008. was founded in 1980. For purposes of this study, data were drawn from the period of 1995-2007. Schwerdtfeger Library staff use a combination of alerts and direct searches of databases and Web sites to confirm new CIMSS publications. These include, but are not limited to, Meteorological and Geoastrophysical Abstracts, Conference Papers Index, Science Citation Index, INSPEC, and NTIS. Once located, all papers are appropriately tagged as "CIMSS" and are regularly uploaded to the Schwerdtfeger Library publications database. A Web site devoted to CIMSS publications is generated from the larger publications database (http://library.ssec.wisc.edu/ resources/cimss/). We used the CIMSS publications site as the source for CIMSS authorships. We then consulted the Science Citation Index for each paper to confirm the author affiliation and the number of times cited. In addition to the categories mentioned above, we created the following categories for data collection:

citation: full citation of the peer-reviewed CIMSS article,

year: publication year,

journal: journal name abbreviation,

number of authors: number of authors on the paper (with at least one author being a CIMSS PI),

times cited: number of times cited, according to the Science Citation Index,

cooperative institutes: Cooperative Institute for Meteorological Satellite Studies, Cooperative Institute for Research in Environmental Sciences (CIRES), Cooperative Institute for Research in the Atmosphere (CIRA), Cooperative Institute for Climate Science (CICS), Cooperative Institute for Oceanographic Satellite Studies (CIOSS),

government agencies: National Oceanic and Atmospheric Administration, National Aeronautics and Space Administration, Environmental Protection Agency (EPA),

other government: other U.S. government agencies, other universities: universities in the United States other than UW-Madison,

foreign universities: foreign universities,

SSEC and other UW departments: collaborators from SSEC and from other departments within UW-Madison,

foreign government: foreign government agencies, UCAR/NCAR: University Corporation for Atmospheric Research (UCAR), National Center for Atmospheric Research (NCAR),

industry: private industry, subjects: categorizes each paper by topic(s). 


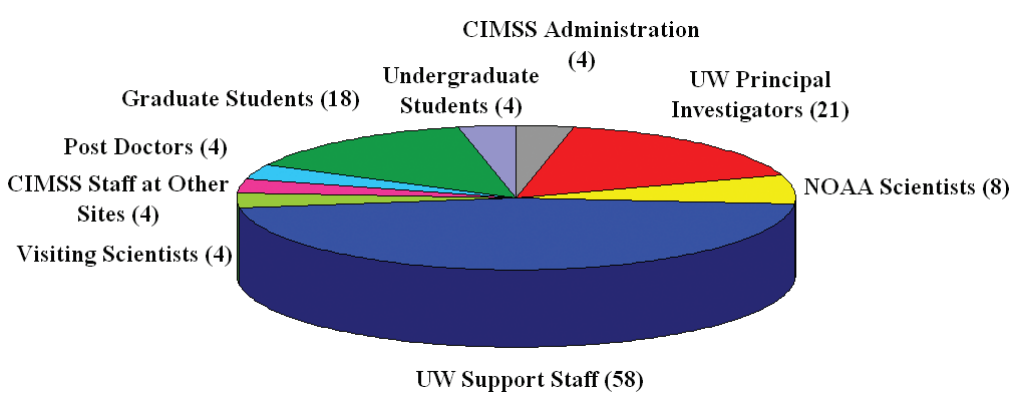

FIG. 2. CIMSS staff distribution, including NOAA scientists with duty stations at UW-Madison.

We developed subject categories of the papers based on title and abstract language, refining them to include the following topics: education; troposphere; remote sensing and satellite observations; clouds and ice clouds; satellite retrievals; hurricanes, tropical cyclones; Geostationary Operational Environmental Satellite (GOES); Moderate Resolution Imaging Spectroradiometer (MODIS); HYDRA; hyperspectral/ ultraspectral measurements/sounders; runoff; instrumentation, Marine-Atmosphere Emitted Radiance Interferometer (M-AERI), Atmospheric Infrared Sounder (AIRS), and lidar; weather forecasting; dust activity, and atmospheric radiation; atmospheric models; Advanced Very High Resolution Radiometer (AVHRR); water vapor; sea surface temperature (SST), ocean-atmosphere interaction; tornadoes, storms; and sea ice. With this categorization, one paper could include more than one subject topic.

Author affiliation information in the Science Citation Index can vary. Sometimes each author on a given article has his/her affiliation listed, but more often than not, the number of affiliations listed does not match the number of authors on the paper. To work with this, we decided to use only the affiliation information given, so that if NOAA is listed twice in the affiliations, we noted "2" under NOAA for that paper. If NOAA was listed once, we noted "1" under NOAA for that paper even though there might have been another NOAA author. Each agency affiliation was handled in this manner. As a result, the number of authors on each paper often does not match the numbers calculated for each agency or group listed. CIMSS authors are represented in various ways in Science Citation Index-for example, as UW-Madison; UW-Madison, SSEC; and/or UW-Madison, CIMSS. Sometimes the affiliation for a CIMSS author is not listed at all. In these cases, we noted those affiliations because we know them (but only for CIMSS authors who are PIs).

PUBLICATION VENUES. As part of this analysis we quantify the journals in which CIMSS scientists choose to publish. Table 1 lists the 10 most frequently chosen in the current analysis. Each journal has its own editorial policy with respect to standards of research, the journal's area of specialization, and its target scientific community. The CIMSS mission goal to serve as a center of excellence in remote sensing is

TABLE I. The top 10 journals chosen by CIMSS scientists, with the impact factor and the number of papers published during 1995-2007.

\begin{tabular}{|c|c|c|}
\hline Journal title & Impact factor* & Papers \\
\hline Journal of Geophysical Research-Atmospheres & 2.953 & 57 \\
\hline Bulletin of the American Meteorological Society & 3.4751 & 48 \\
\hline Journal of Applied Meteorology (includes JAMC) & 1.888 & 37 \\
\hline Monthly Weather Review & 2.267 & 32 \\
\hline Journal of Atmospheric and Oceanic Technology & 1.564 & 24 \\
\hline Weather and Forecasting & 1.375 & 22 \\
\hline Geophysical Research Letters & 2.744 & 21 \\
\hline Atmosphere-Ocean & 1.920 & 19 \\
\hline Applied Optics & 1.701 & 19 \\
\hline IEEE Transactions on Geoscience and Remote Sensing & 2.344 & 15 \\
\hline Journal of Quantitative Spectroscopy and Radiative Transfer & 1.972 & 12 \\
\hline
\end{tabular}

* According to Journal Citation Reports published by Thomson Reuters, the journal impact factor is the average number of times articles from the journal published in the past two years have been cited in the JCR year (2007). 
indicated by the journals that publish CIMSS papers (Table 1). The scientific focus of the journals listed in Table 1 encompasses the subject areas of satellite remote sensing in both theory and application.

CIMSS authors publish $87 \%-89 \%$ of their articles with professional societies such as the American Meteorological Society (AMS) and the American Geophysical Union (AGU). During the period of 1995-2007, CIMSS authors published 51 articles, or $12.3 \%$, with commercial publishers like Elsevier, Springer, and Blackwell. The AMS, as the main professional society for the atmospheric sciences, offers a range of relevant and respected peer-reviewed journals that reach the appropriate audiences; thus, a higher percentage of papers are published with the society. Unlike most commercial publishers, the AMS has made a moving wall of its material freely available to anyone without a subscription (see sidebar). This arrangement is beneficial to the scientific community because it promotes broad access to electronic manuscripts. Authors still transfer copyright to the society but retain some rights for certain uses of their work, a middle ground between transfer of all rights to the publisher and total retention of copyright, allowing the publisher certain rights. Finally, from 1986 to 2002 , journal prices rose $227 \%$ and book prices rose $75 \%$ compared to the rise in the consumer price index (CPI) of $64 \%$ over the same period (Bergman 2006). This is especially true of commercial journal publishers in the sciences.

ANALYSIS. Figure 3 shows the number of publications found from 1995 through 2007. CIMSS has published more than 400 articles in refereed journals and more than 1,000 publications in conference proceedings. Abt (2007) says that the "average annual number of papers per scientist has remained constant [in five fields ... including AGU journals] during two generations of scientists." Thus, the increase in publications in refereed journals since 1995 is expected with the growth of the institute. However, the average number of publications per CIMSS principal investigator has also increased. The peer-reviewed publication per PI in 1995 was less than 2 and has grown to 3.4 in 2007. The percentage of peer-reviewed publications to the total publications (peer reviewed plus conference) ranges between $22 \%$ and $37 \%$, depending on the year. In general, the trend shows a steady increase in the

\section{OPEN ACCESS PUBLISHING}

The academic publishing world is changing. It is not uncommon to find full-text documents available online at the Web sites of authors. There are a growing number of open-access (OA) journals.

A fully open-access journal is a publication using a funding model that does not charge readers or their institutions for access and in which the author retains control of copyright. Any individual user may read, download, and print the digital content of an open access article. There is evidence (e.g., Harnad and Brody 2004; Norris et al. 2008) that in some fields of study open-access articles are more often cited than those from "toll access" (TA). Norris et al. (2008) state

Of a sample of 4,633 articles examined, 2,280 (49\%) were OA and had a mean citation count of 9.04 whereas the mean for (toll access) TA articles was 5.76. There appears to be a clear citation advantage for those articles that are $O A$ as opposed to those that are TA. This advantage, however, var- ies between disciplines, with sociology having the highest citation advantage, but the lowest number of $\mathrm{OA}$ articles, from the sample taken, and ecology having the highest individual citation count for $O A$ articles, but the smallest citation advantage. Tests of correlation or association between OA status and a number of variables were generally found to be weak or inconsistent. The cause of this citation advantage has not been determined.

The open access movement is gaining momentum as it becomes increasingly more difficult to sustain the traditional publishing model. In January 2008, the University of California, Berkeley, launched the
Berkeley Research Impact Initiative, a pilot program that covers publication charges for open-access journals. The University of Wisconsin-Madison libraries have established a fund to partially cover open access submission costs for authors wishing to publish in those venues.

Additionally, many universities are encouraging their faculty to consider and support alternative forms of publication and explore new models of scholarly publishing that not only allow access but also have adopted a copyright policy that encourages authors to retain control of their intellectual property (see www.library.wisc.edu/scp/copyright/ author_addendum.pdf).

\section{For more information:}

Scholarly Communication (Committee on Institutional Cooperation): www.cic.net/Home/Projects/Library/ScholarlyComm/Introduction.aspx

SPARC: The Scholarly Publishing and Academic Resources Coalition: www.arl.org/sparc/

Scholarly Communication and Publishing (University of Wisconsin-Madison Libraries): www.library.wisc.edu/scp/copyright/ 


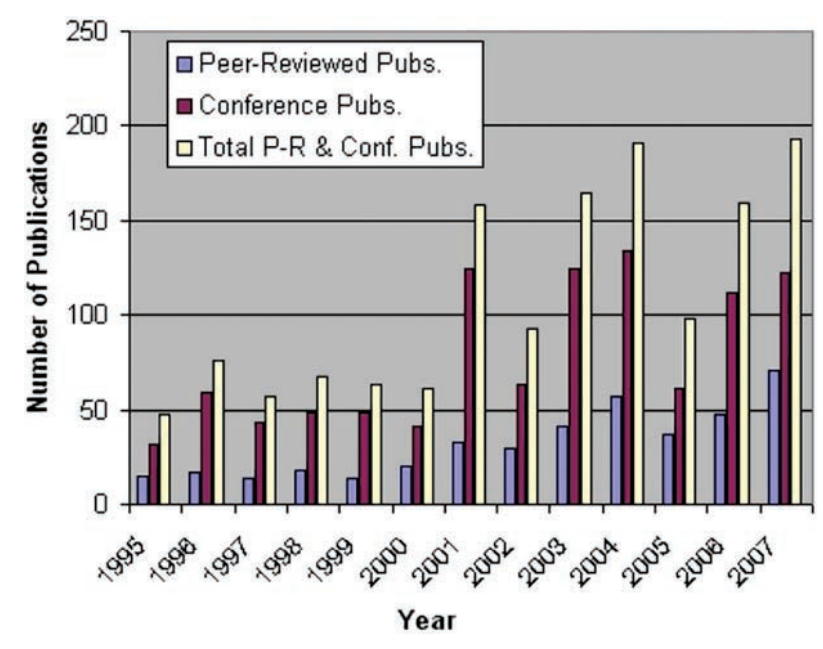

FIG. 3. The number of publications by CIMSS scientists between 1995 and 2007.

percentage of peer-reviewed literature (which may mean that a greater number of conference papers are making their way into the reviewed literature, but this was not examined). Since 1999, there is an appearance of a 3-yr cycle in publications, with local peaks in 2001 and 2004 and perhaps again in 2007. The AMS-sponsored conferences in satellite meteorology in 2001, 2003, 2004, 2006, and 2007 are clearly seen in the histogram of conference proceedings. The following sections explore the publication record of peer-reviewed papers with reference to the three mission statements of the institute, summarized as collaborative research, center of excellence, and education.

Collaborative research. One metric of the CIMSS mission to foster collaborative research is to quantify the number of collaborative publications in general, and those with NOAA employees in particular. Our strongest coauthor partnership is with NOAA (Fig. 4), with more than $40 \%$ of CIMSSpublished papers having one or more coauthors from NOAA. Approximately $24 \%$ of the publications are coauthored with NASA collaborators. During the period of 1995-2007, there were 347 federal scientists as coauthors on 414 peer-reviewed papers.

The second most common collaborations are with scientists from other universities. A total of 148 papers were published with scientists at other universities within the United States. There are only sporadic joint

\footnotetext{
${ }^{1}$ The affiliation of the CIMSS Director is listed under CIMSS and not AOS. This would more than double the rate of publications with AOS.
}

publications with faculty from the UW-Madison Department of Atmospheric and Oceanic Sciences, although they have recently been consistent at about three per year in the last $3 \mathrm{yr}^{1}{ }^{1}$ Graduate students from the Department of Atmospheric and Oceanic Sciences are featured as coauthors under CIMSS affiliations because principal investigators frequently hire graduate students as team members. This does not provide appropriate recognition to AOS, and given the close relationship between CIMSS and AOS, future publications with graduate students will list AOS as an institute.

Interestingly, there are no collaborations with other NOAA cooperative institutes (CIs) until the year 2000. The overlap in collaborative publications with other cooperative institutes is as follows: CIRES: 15 papers (3.4\%); CIRA: 13 papers (2.9\%); CICS: 1 paper $(0.02 \%)$; CIOSS: 0 papers. CIOSS is a new CI and focuses on oceanography so the lack of collaborative publications is not surprising. Similarly, research topics marginally overlap with CICS. We have strong collaborations with the National Environmental Satellite Data and Information Service (NESDIS) institute at CIRA as reflected in the 13 collaborative papers. The number of publications with CIRES was noteworthy because it is a NOAA institute but not a NESDIS institute, as is CIMSS. The number of publications with CIRES is steady at about two per year since the year 2000. The distribution of publications with CIRA varies from one to four in a given year.

CIMSS has a strong international presence in remote sensing, particularly in the analysis of polar orbiting satellite data. This recognition is reflected in the 69 papers published with foreign partners and the 47 papers published with industry. Many of these publications reflect CIMSS' international collaborations in a variety of satellite programs.

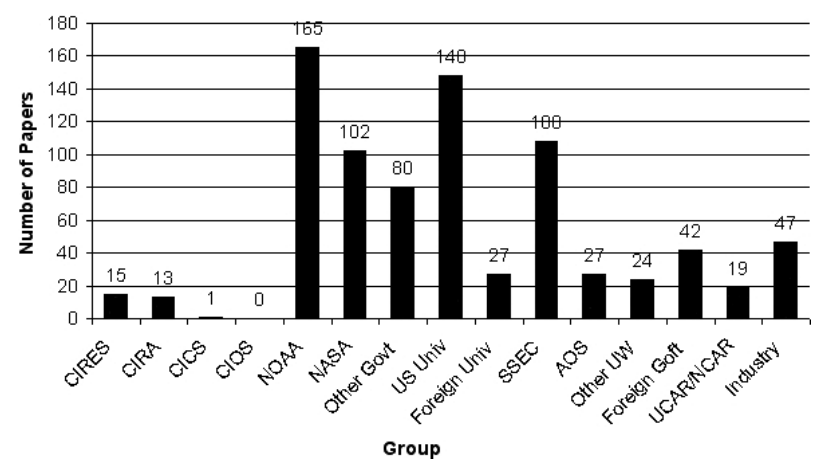

FIG. 4. The number of papers with coauthors from various institutes during the years 1995-2007. Note that in this figure a single paper can be counted multiple times in the case of multiple authors. 
Center of excellence. The second mission statement of CIMSS addresses its goal of developing an internationally recognized center with expertise in satellite remote sensing and applications. By constructing thematic groups, we can make some assessment about continuing, receding, and emerging research areas. Figure 5 breaks out the yearly number of publications dealing with particular research topics. Many of CIMSS publications deal with satellite instruments (GOES, MODIS, AVHRR, AIRS) as well as groundbased measurement systems (e.g., AERI, M-AERI, and lidars).

The impact of new associates and hires is evident in publications. For example, prior to 2000 there were about five papers per year that dealt directly with cloud observations. Within the last $8 \mathrm{yr}$, a group of cloud remote sensing experts came to CIMSS and began building a research group in this area. Since
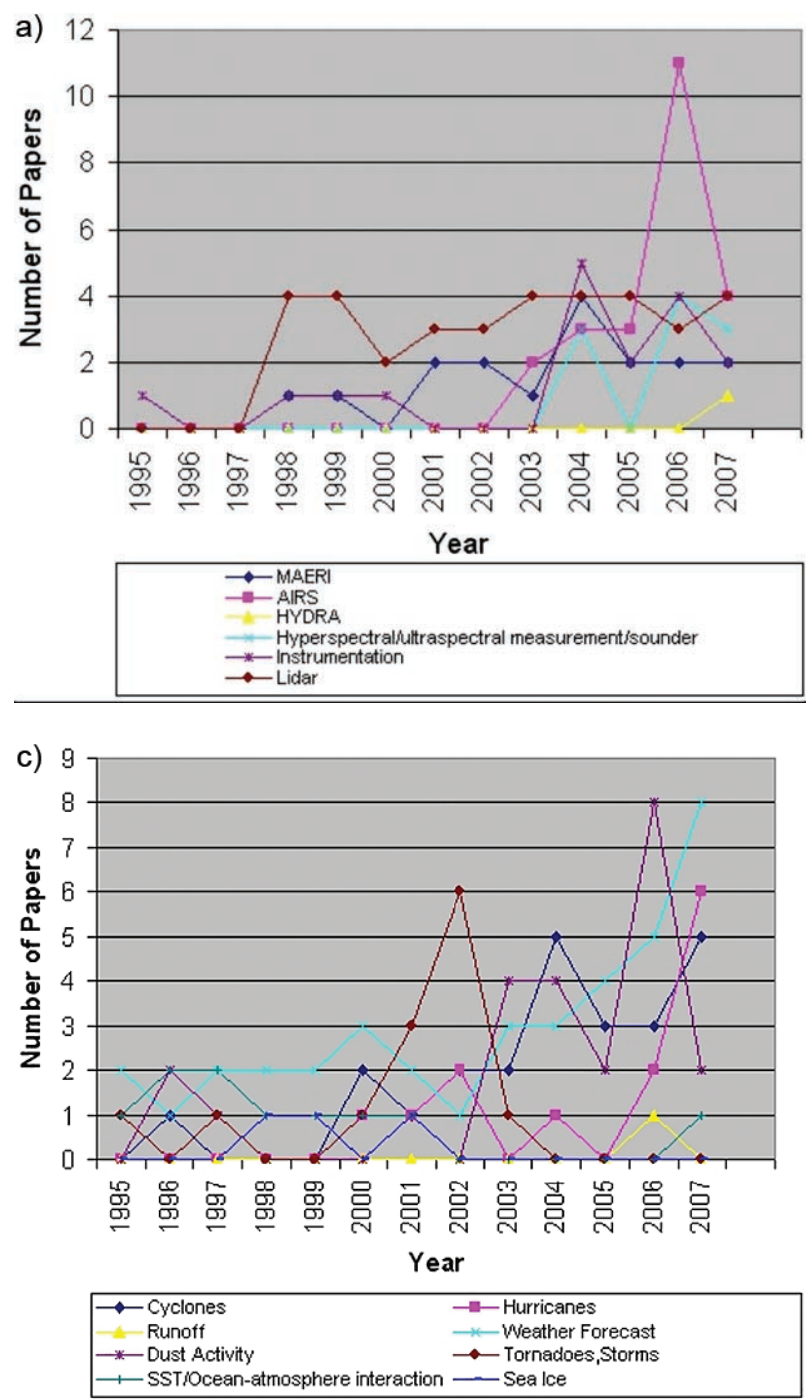

2004, the publications dealing with clouds are 10 per year or more. An increase in the number of publications dealing with MODIS (first launched in 1999 and another in 2001) occurred in 2002-04 (10 in 2004 and 8 in 2003). A peak is also seen in the post-AIRS launch (2001). The number of publications dealing with the GOES satellite series varies between 0 and 12 per year. Historically, CIMSS has exhibited strong research in hurricanes and cyclones, showing a recent upward trend in publication rates. The number of publications directly dealing with weather forecasting has grown steadily since 2002, from about two per year to eight per year.

We compiled the top 15 most highly cited papers in the CIMSS publications record (not shown). All of these papers were cited more than 50 times, with over 200 citations for the most referenced paper. None of the 15 papers are single-author papers and all but
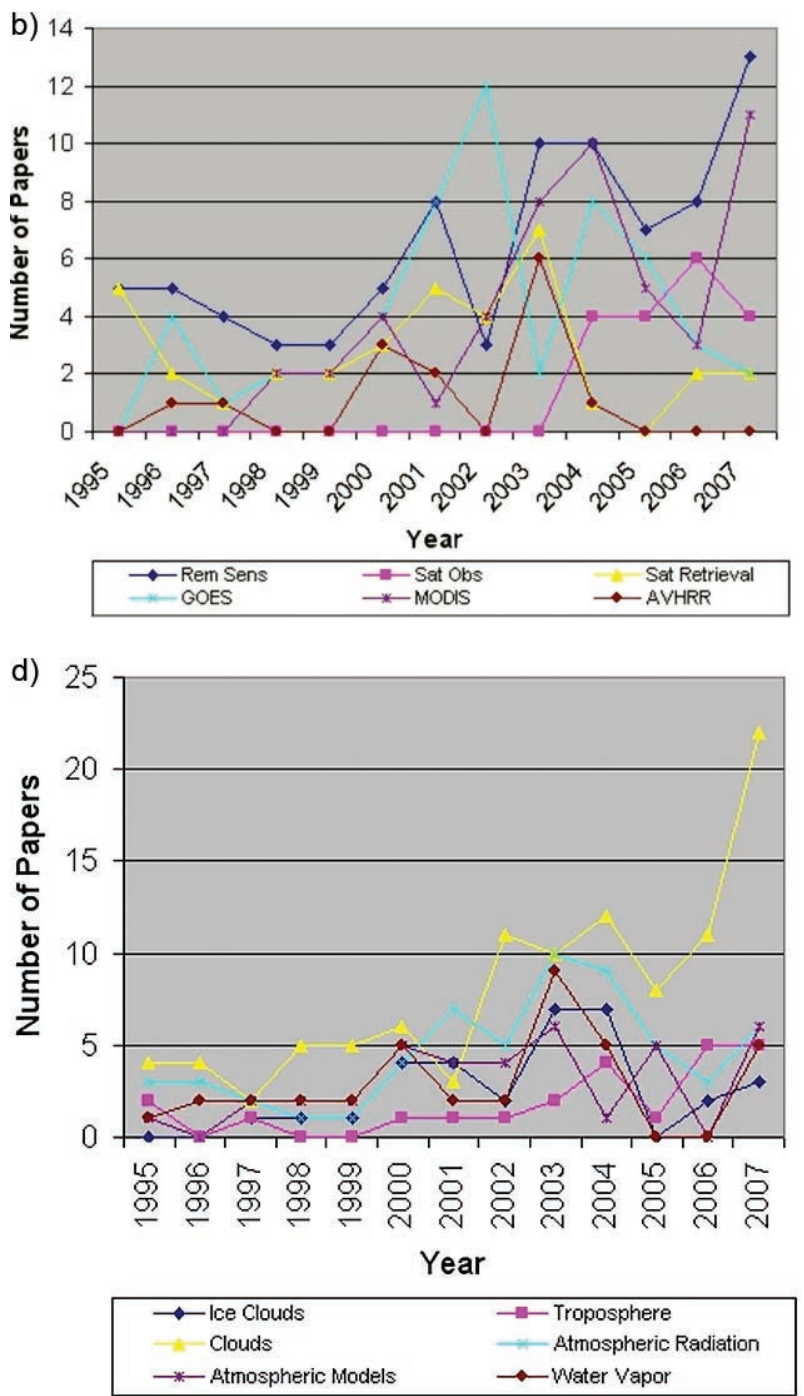

FIG. 5. Publication trends in some of the CIMSS research topics. 
one include more than four coauthors. Among the 15 papers, one author appears nine times. Four of the papers include a CIMSS scientist as first author. A review of paper topics indicates that most fall into the category of reporting results for a field program or outlining a data analysis procedure for satellite observations. These types of papers provide important information on observational data and data analysis practices for common use and often represent a culmination of previous research. Each type of paper includes multiple authors due to the involvement of a broad scientific community.

The Hirsch index (Hirsch 2005), or $h$ index, attempts to measure the scientific productivity and impact of a scientist. As a reference, it is suggested that a value of 18 is appropriate for a full professor. Looking at the $h$ index for the top four authors (mentioned above), we find that 1 ) the $h$-index values range from 9 to 24,2) total publications for the four authors ranges from 10 to 85 , and 3 ) the corresponding average number of citations per item ranges from 21 to 57.

Education. Because CIMSS is a research center within a research university, one might assess its education mission by the number of papers that include a graduate student as a collaborator. Tabulating student papers is not straightforward due to delays in publication after graduation. We determined the number of publications by students as any journal article published within two years after graduation. Figure 6 shows this history, with the number ranging from 0 to 10 papers published per year by graduate students. This is smaller than the total number of M.S. and Ph.D. degrees awarded each year, indicating that some are not finding a way into the peer-reviewed literature or occur more than $2 \mathrm{yr}$ after graduation.

Since 1990 CIMSS has offered summer workshops for high school students and teachers and international workshops in satellite remote sensing throughout the year. In collaboration with AOS, the Institute now hosts two online courses for $\mathrm{K}-12$ teachers. We anticipated finding peer-reviewed papers on atmospheric science education topics, but the results do not bear this out, with only three publications in the entire period. Although CIMSS' educational programs are a topic of conference papers (e.g., the AMS 17th Symposium on Education in 2007 had six education papers with CIMSS authors), they have not been developed and submitted to refereed journals. There are journals of education in the geosciences, but none specific to the atmospheric sciences. Many of the

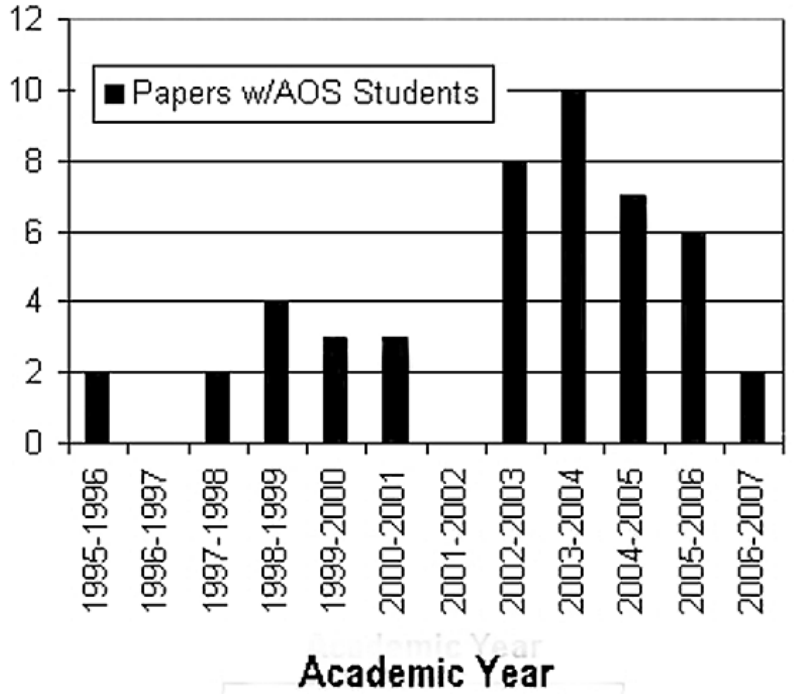

FIG. 6. Number of refereed journal articles by graduate students, within 2 yr of graduation.

CIMSS education projects do not feature research in pedagogy, teaching methods, or curriculum development. Results from workshops and international classes are important but not ground-breaking education research, which may limit publication options for CIMSS.

CONCLUSIONS. Academic institutions, federal agencies, and researchers use publication analysis to support promotion, tenure, and funding decisions (e.g., Meho and Yang 2006). This article uses bibliometric methods to examine the mission success of a federally funded research center.

A methodology is defined that facilitates examination of the number of publications, patterns in research, collaborations, classification of topics, and publishing venues. Using this categorization, an assessment was made on how publications reflect the institute's mission goals of 1) fostering collaborative research, 2) becoming a center of excellence, and 3) educating scientists and students. Our findings indicate that a self-study of publishing activities yields useful results about programmatic strengths and weaknesses.

The institute mission of collaboration is being met as determined by the coauthorship with NOAA and NASA: more than $40 \%$ of CIMSS publications are coauthored with NOAA scientists and $24 \%$ are coauthored with NASA scientists. There is also a positive trend to publish more with other cooperative institutes of the NOAA program.

The increasing numbers of both total publications and publications with international partners and 
universities reflect the institute's mission goal to be a center of excellence. The number of publications per scientist has increased from less than two to more than three per year over the 12 -yr period. Many CIMSS publications deal with satellite-based as well as ground-based measurement systems. An increase in the number of publications of a satellite instrument is observed post launch. Historically, CIMSS has exhibited strong research in hurricanes and cyclones, showing a recent upward trend in publication rates. The impact of new associates and hires is evident in publications. The number of publications directly dealing with weather forecasting has grown steadily since 2002.

The institute's education mission is addressed through the number of publications by graduate students, although the trend in later years is not encouraging and needs to be reversed. The number of education papers is small and is not representative of the many education activities at CIMSS. Many conference papers on education activities are not being published in peer-reviewed journals, and this may be due to the lack of an appropriate publishing venue.

We found publication analysis to be a useful metric with specific regard to the threefold CIMSS mission of fostering collaborative research, becoming a center of excellence, and educating scientists and students. Some federal agencies, including NOAA, are requiring quantification of performance as it relates to an organization's mission goals. Some of the measures include publication and citation analysis and partner- ships. This study may be the first step of a broaderbased evaluation of cooperative institute performance that could have value for federal government research and programmatic evaluation.

ACKNOWLEDGMENTS. This work was supported, in part, by a grant from Thomson Scientific and NOAA NESDIS Grant NA06NES4400002.

\section{REFERENCES}

Abt, H. A., 2007: The publication rate of scientific papers depends only on the number of scientists. Scientometrics, 73, 281-288.

Bergman, S. S., 2006: The scholarly communication movement: Highlights and recent developments. Collection Build, 25, 108-128.

Harnad, S., and T. Brody, 2004: Comparing the impact of open access (OA) vs. non-OA articles in the same journals. D-Lib Mag., 10 (6). [Available online at www.dlib.org/dlib/june04/harnad/06harnad.html.]

Hirsch, J. E., 2005: An index to quantify an individual's scientific research output. Proc. Natl. Acad. Sci. USA, 102, 1656916572, doi:10.1073/pnas.0507655102.

Kostoff, R. N., 2002: Citation analysis of research performer quality. Scientometrics, 53, 49-71.

Meho, L. I., and K. Yang, 2007: Citation analysis: A comparison of Google Scholar, Scopus, and Web of Science. J. Amer. Soc. Inform. Sci. Tech., 43, 1-15, doi:10.1002/meet.14504301185.

Norris, M., C. Oppenheim, and F. Rowland, 2008: The citation advantage of open-access articles. J. Amer. Soc. Inform. Sci. Technol., 59, 1963-1972. 